\title{
Liquefaction of Heterogeneous Soil: Centrifuge Study
}

\author{
Pradipta Chakrabortty, Radu Popescu \\ Engineering and Applied Science, Memorial University of Newfoundland, St. John's, NL Canada
}

Ryan Phillips, Hesham Dief

C-CORE, St. John's, NL, Canada

Keywords: Heterogeneous soil, Liquefaction, centrifuge test

ABSTRACT: A series of centrifuge liquefaction tests have been conducted at C-CORE's geotechnical centrifuge facility: two on variable soil and one on uniform soil deposits. A single storied frame structure resting on two strip footings was also placed on that soil deposit. Experimental results such as accelerations, excess pore water pressures (EPWP) and settlements were monitored throughout the tests. Recorded results support the conclusion of previous research that more EPWP is generated in heterogeneous soil deposits than in the corresponding homogeneous soil. The mechanism of this phenomenon is discussed in this paper.

\section{Introduction}

Soil variability and uncertainty in soil properties are common challenges in geotechnical engineering design. Soil properties of a natural deposit not only vary in the vertical direction but they could also vary in the horizontal direction. From past research it was observed that soil heterogeneity not only induced variability in the computed response, but also changes the failure mechanism (Popescu et al., 2005). It was also observed that more excess pore water pressure (EPWP) is generated during an earthquake in a heterogeneous soil deposit than in a homogeneous soil with equivalent average geo-mechanical properties. This interesting phenomenon first observed in small scale laboratory tests (Budiman et al., 1995; Konrad and Dubeau, 2002), and later in numerical modelling (Popescu et al., 1997; Popescu et al., 2006; Popescu and Chakrabortty, 2006) and centrifuge tests (Ghosh and Madabhushi, 2003).

The two small scale laboratory test results mentioned in the previous paragraph were based on undrained cyclic triaxial tests on samples made of different types of soil (Budiman et al., 1995 used sand mixed with gravel; and Konrad and Dubeau (2002), used layered sand and silt samples). A detailed numerical analysis of the triaxial tests on sand and silt uniform and layered samples (Konrad and Dubeau, 2002) was performed by Chakrabortty et al. (2004) using the finite element code DYNAFLOW (Prevost, 2002). From the study it was found that water was squeezed out from the more deformable silt layer and injected into the neighbouring dense sand layer, inducing early liquefaction of the dense sand. This phenomenon is similar to injecting water into a sample during undrained triaxial tests as reported by Atigh and Byrne (2004), Vaid and Eliadorani (1998). Liquefaction mechanism of a heterogeneous soil deposit involving one type of soil material but with a localised loose pocket was explained by Ghosh and Madabhushi (2003), using a series of centrifuge experiments. It was observed that EPWP is generated in the loose sand pockets first and then the water migrates into the neighbouring dense soil, and softens the dense soil by reducing the effective stress. This phenomenon has been studied and explained in more details using numerical simulation of different types of heterogeneous soil models by Popescu et al. (2006), and Popescu and Chakrabortty (2006). However, a limited number of experimental verifications are available to date to the practicing engineering community to help in recognizing, quantifying and accepting the abovementioned behaviour of heterogeneous soils. Therefore the major objective of the present study is to validate the numerical findings for a boundary value problem by performing a series of geotechnical centrifuge tests on heterogeneous liquefiable soil models.

A series of three centrifuge tests have been performed in this study: one on homogeneous soil and two on heterogeneous soil. The test on uniform soil is performed on a soil deposit with the soil properties which are looser/softer than the average geo-mechanical properties of heterogeneous soil deposit. The results such as EPWP, accelerations, settlements are monitored throughout the test duration. Recorded results support the conclusion of previous research that more EPWP is generated in a heterogeneous soil deposits than in the corresponding homogeneous soil. From this study it is also concluded that although the heterogeneous soil deposit was, on average, denser than the uniform soil deposit, the liquefaction resistance of heterogeneous soil was lower than that of the uniform soil due to water migration from loose to dense soil pockets. 


\section{Soil Properties and centrifuge models:}

The soil for centrifuge experiments is selected from the Fraser River Delta in British Columbia, a densely populated region highly vulnerable to earthquake hazards and soil liquefaction. Fraser River sand received a lot of research attention because of important seismic activity and high liquefaction susceptibility in a densely populated area. The Fraser River sand is a grey coloured medium grained sand, and is comprised of $40 \%$ quartz, quartzite and chert, $11 \%$ feldspar, and $45 \%$ unstable rock fragments. The soil grains are angular to sub-rounded (Vaid and Sivathayalan, 1996). The batch of the sand used here had an average particle size $\mathrm{D}_{50}$ of $0.26 \mathrm{~mm}$ with fine content (passing \#200-sieve) of $0.4 \%$. The maximum and minimum void ratios are 0.94 and 0.62 , respectively. The specific gravity of this sand is 2.71 (C-CORE, 2005). A 20-25mm thick drainage layer was placed before raining the sand. In the drainage layer, coarse sand with particle size larger than $1 \mathrm{~mm}$ has been used. This drainage layer was used to uniformly distribute the fluid throughout the sample during saturation.

Three liquefaction tests were conducted on Fraser River sand at 70g's to determine the prototype behaviour of heterogeneous soil in a centrifuge model. The internal dimensions of the model container are $73.7 \mathrm{~cm}$ (length) $x$ $28.7 \mathrm{~cm}$ (width) $\times 57 \mathrm{~cm}$ (depth). Accelerometers, pore pressure transducers and LVDTs were monitored throughout the tests which include the use of a viscosity scaled pore fluid to ensure that the time scaling factor for dynamic phenomena is the same as that for dissipation phenomena. The first of the three centrifuge tests was performed on a medium dense homogeneous soil (relative density $D_{r}=55 \%$ ). A $16 \mathrm{~m}$ deep (prototype scale) medium dense sand deposit is overlying a $4 \mathrm{~m}$ deep dense $\left(D_{r}=75 \%\right)$ sand layer. A framed structure resting on two strip footings is placed on that soil deposit. The characteristic frequency of the structure is $2.1 \mathrm{~Hz}$ (at prototype scale). The bearing pressure below footings is $110 \mathrm{kPa}$ at $70 \mathrm{~g}$. The synthetic earthquake time history used in the centrifuge experiments was selected as the $2 \%$ earthquake in 50 years for Vancouver area based on the firm ground target spectrum in NBCC (2005). It was then amplified by 1.46 to obtain a peak ground acceleration of $0.25 \mathrm{~g}$ during centrifuge tests. Locations of all the transducers in $x-y-z$ coordinates are shown in Table 1. A $5.4 \mathrm{~cm}$ thick (model scale) duxseal layer has been placed at the two transversal walls of the rigid box to reduce boundary effects by partially preventing wave reflection.

The second and third tests were performed on heterogeneous soil. In both models, $2 \mathrm{~m}$ thick loose soil $\left(D_{r}=35 \%\right)$ pockets are placed within a $16 \mathrm{~m}$ deep dense soil $\left(D_{r}=75 \%\right)$ deposit. This heterogeneous soil is overlying a $4 \mathrm{~m}$ thick dense soil layer. The same structure is also placed on the heterogeneous soil to find the effect of soil heterogeneity on the seismic responses. Table 1 shows the locations of all the transducers in $x-y-z$ coordinates. The model configurations with the transducer locations for uniform and variable soil are shown in Figure 1.

Table1: Locations of the transducers used in the centrifuge tests (at prototype scale)

\begin{tabular}{|c|c|c|c|c|c|c|c|c|c|c|c|}
\hline \multirow[b]{2}{*}{$\begin{array}{l}\text { Instrument } \\
\text { Type }\end{array}$} & \multirow[b]{2}{*}{ Label } & \multicolumn{3}{|c|}{ Test1 } & \multicolumn{3}{|c|}{ Test2 } & \multicolumn{3}{|c|}{ Test3 } & \multirow[b]{2}{*}{ Remarks } \\
\hline & & $\begin{array}{c}X \\
(\mathrm{~m})\end{array}$ & $\begin{array}{c}\mathrm{Y} \\
(\mathrm{m})\end{array}$ & $\begin{array}{c}\mathrm{Z} \\
(\mathrm{m})\end{array}$ & $\begin{array}{c}\mathrm{X} \\
(\mathrm{m})\end{array}$ & $\begin{array}{c}\mathrm{Y} \\
(\mathrm{m})\end{array}$ & $\begin{array}{c}\mathrm{Z} \\
(\mathrm{m})\end{array}$ & $\begin{array}{c}X \\
(\mathrm{~m})\end{array}$ & $\begin{array}{c}\mathrm{Y} \\
(\mathrm{m})\end{array}$ & $\begin{array}{c}\mathrm{Z} \\
(\mathrm{m})\end{array}$ & \\
\hline \multirow{12}{*}{ 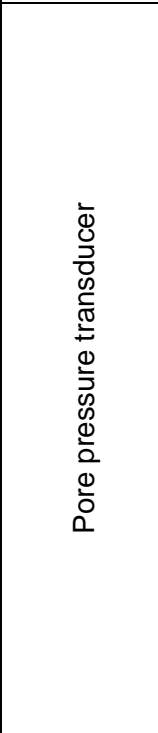 } & P1 & - & - & - & - & - & - & 36.5 & 17 & 12 & \\
\hline & P2 & 36.8 & 15 & 9 & 36.5 & 15 & 12 & 36.5 & 15 & 8 & \\
\hline & P3 & 36.8 & 11 & 6 & 36.5 & 11 & 8 & 36.5 & 11 & 12 & $\begin{array}{l}\text { Not recorded } \\
\text { correctly due to } \\
\text { saturation } \\
\text { problem in test2 }\end{array}$ \\
\hline & P4 & - & - & - & - & - & - & 36.5 & 9 & 8 & \\
\hline & P5 & 13.8 & 17 & 7 & 13.6 & 17 & 7 & 13.6 & 17 & 7 & $\begin{array}{l}\text { Not working in } \\
\text { test1 }\end{array}$ \\
\hline & P6 & 13.8 & 15 & 3 & 13.6 & 15 & 3 & 13.6 & 15 & 3 & $\begin{array}{l}\text { Not recorded in } \\
\text { test3 }\end{array}$ \\
\hline & $\mathrm{P} 7$ & 13.8 & 11 & 7 & 13.6 & 11 & 7 & 13.6 & 11 & 7 & $\begin{array}{l}\text { Not recorded } \\
\text { after EPWP ratio } \\
\text { exceeds } 0.4 \text { in } \\
\text { test1 }\end{array}$ \\
\hline & P8 & 13.8 & 9 & 3 & 13.6 & 9 & 3 & 13.6 & 9 & 3 & \\
\hline & P9 & - & - & - & - & - & - & 13.6 & 17 & 17 & \\
\hline & P10 & - & - & - & - & - & - & 13.6 & 15 & 13 & \\
\hline & P11 & - & - & - & - & - & - & 13.6 & 11 & 17 & $\begin{array}{l}\text { Not recorded in } \\
\text { test3 }\end{array}$ \\
\hline & P12 & - & - & - & - & - & - & 13.6 & 9 & 13 & \\
\hline \multirow{4}{*}{$\stackrel{5}{9}$} & L1 & 36.3 & 26 & 9 & 36.1 & 26 & 12 & 36.1 & 26 & 12 & \\
\hline & $\mathrm{L} 2$ & 32.3 & 26 & 5 & 32.1 & 26 & 8 & 32.1 & 26 & 8 & \\
\hline & L3 & - & - & - & - & - & - & 21 & 20.2 & 15 & \\
\hline & L4 & - & - & - & - & - & - & 13.6 & 20.2 & 15 & \\
\hline
\end{tabular}




\begin{tabular}{|c|c|c|c|c|c|c|c|c|c|c|c|}
\hline \multirow{8}{*}{ 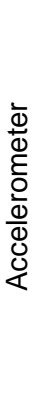 } & A1 & \multicolumn{3}{|c|}{$\begin{array}{l}\text { Base of the box } \\
\text { (Input) }\end{array}$} & \multicolumn{3}{|c|}{$\begin{array}{l}\text { Base of the box } \\
\text { (Input) }\end{array}$} & \multicolumn{3}{|c|}{$\begin{array}{l}\text { Base of the box } \\
\text { (Input) }\end{array}$} & \\
\hline & A2 & \multicolumn{3}{|c|}{$\begin{array}{l}\text { Base of the box } \\
\text { (vertical) }\end{array}$} & \multicolumn{3}{|c|}{$\begin{array}{l}\text { Base of the box } \\
\text { (vertical) }\end{array}$} & \multicolumn{3}{|c|}{$\begin{array}{l}\text { Base of the box } \\
\text { (vertical) }\end{array}$} & $\begin{array}{l}\text { Not recorded in } \\
\text { test1 }\end{array}$ \\
\hline & A3 & 36.8 & 26 & 7 & 36.5 & 26 & 10 & 36.5 & 26 & 10 & \multirow{6}{*}{$\begin{array}{l}\text { No accelerations } \\
\text { recorded in } \\
\text { test2; } \mathrm{A} 3 \text { not } \\
\text { recorded in test3 }\end{array}$} \\
\hline & A4 & 36.8 & 19 & 12 & 36.5 & 19.3 & 10 & 36.5 & 19.3 & 10 & \\
\hline & A5 & 11.8 & 11 & 5 & 22.8 & 13.7 & 5 & 11.6 & 11 & 5 & \\
\hline & A6 & - & - & - & - & - & - & 11.6 & 15 & 15 & \\
\hline & A7 & 11.8 & 19 & 5 & 11.6 & 19.1 & 5 & 11.6 & 19 & 5 & \\
\hline & A8 & 15.6 & 17.6 & 5 & 15.5 & 17.8 & 5 & 11.6 & 17.6 & 5 & \\
\hline
\end{tabular}

\section{Sample preparation:}

All the tested models were prepared by air pluviation of Fraser River sand into the model container using a hopper (shown in Figure 2). First, the drainage layer was placed inside the rigid box. Next, a 54mm thick duxseal layer was placed at the side walls perpendicular to the direction of seismic acceleration. The relative density of the soil was controlled by the falling height of the sand. During model preparation the hopper speed was kept constant at about $10 \mathrm{~cm} / \mathrm{sec}$. The relation between falling height and sand relative density is shown in Figure 3 . When the sand deposit reached the selected height for the transducer, sand raining was stopped to place the accelerometers and the pore pressure transducers. Pore pressure transducers were placed within the soil deposit with the plane of their porous stones oriented vertically and the transducers parallel to the direction of shaking. There are 16 loose pockets at 8 different depths inside heterogeneous soil. The loose pockets at the same height were constructed first. Then the spaces between two loose pockets or one loose pocket and the duxseal near lateral wall of box were filled with dense soil.

a)
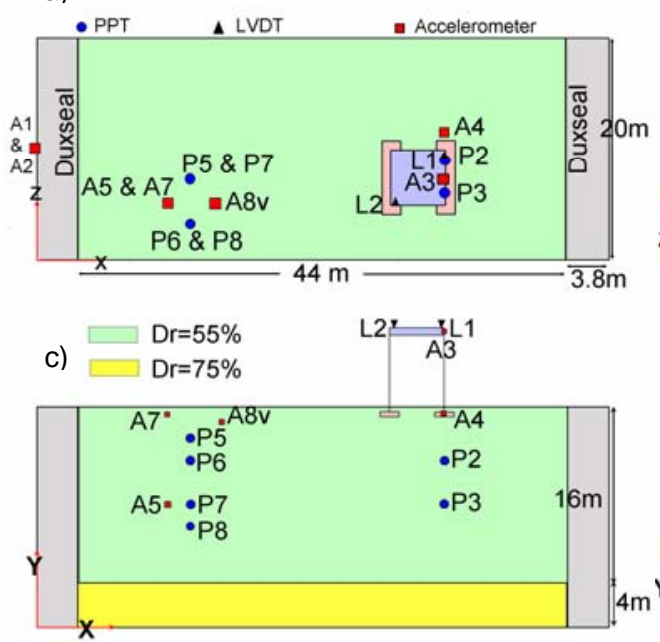

b)

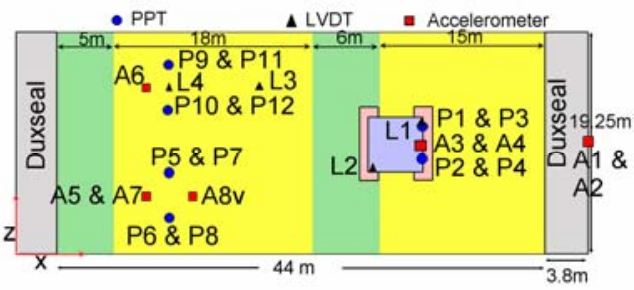

d)

Figure 1. Schematic drawing of centrifuge tests a) plan: test1 b) plan: test3 c) elevation: test1 d) elevation: test3 


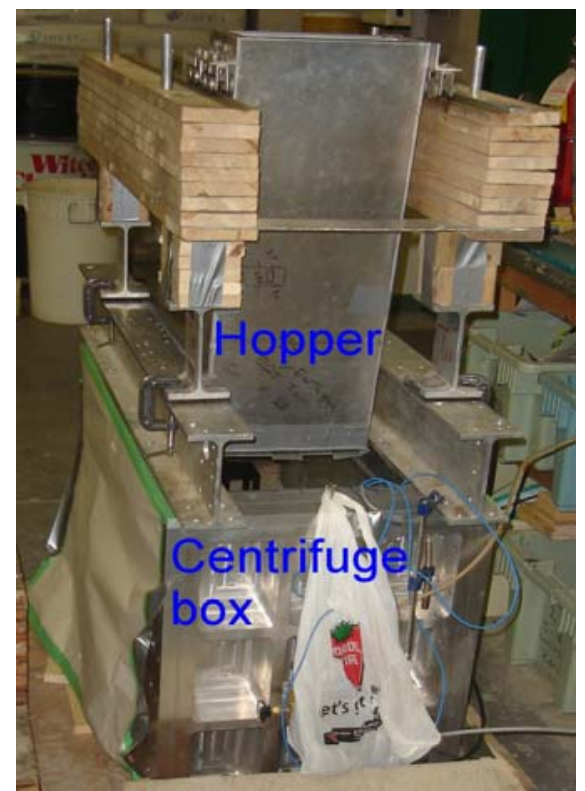

Figure 2. Setup for sand raining during test 2

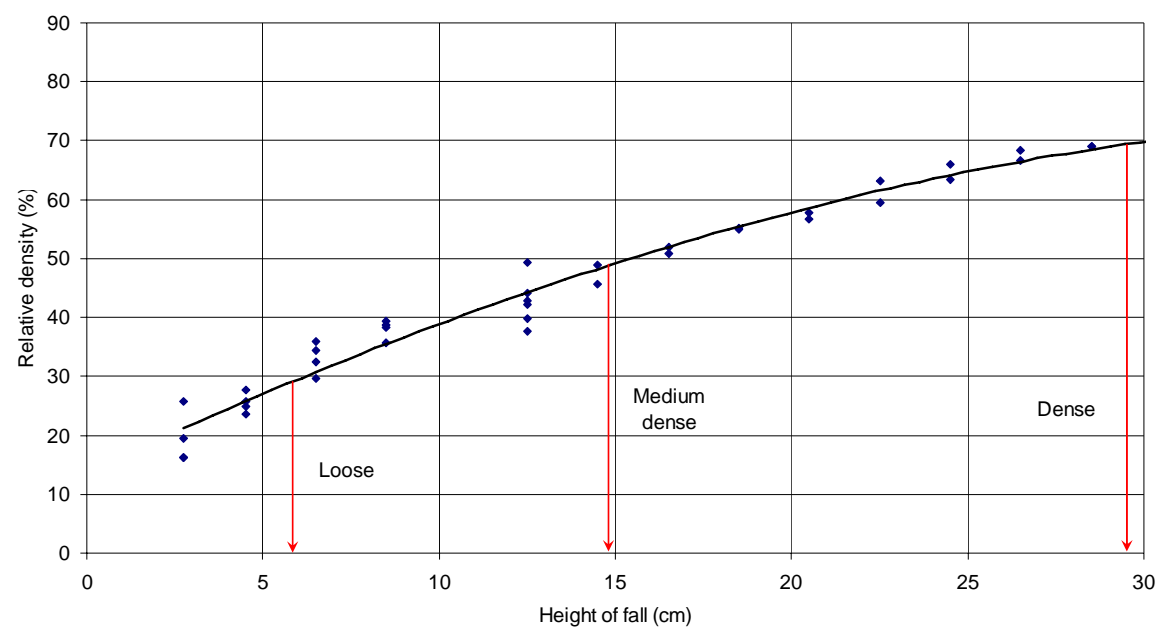

Figure 3. Sand falling height vs. relative density relation

\section{Results and Discussion:}

The measured EPWP are presented in terms of their ratio with respect to the initial vertical effective stress $\left(\sigma^{\prime}{ }_{\mathrm{v}}\right)$ at the transducer locations (EPWP ratio=EPWP $/ \sigma_{\mathrm{v}}^{\prime}$ ). A comparison of the evolution of EPWP ratio below the structure and in the free field between medium dense uniform soil and loose soil pocket in heterogeneous soil is shown in Figure 4. The values shown in Figure 4a, recorded below structure are in general smaller than those recorded at similar depths in the free field and shown in Figure $4 \mathrm{~b}$. This is believed to be due to higher initial effective stress below the structure. It is also obvious from Figure 4 that pore pressure generated in the heterogeneous soil (Tests 2 and 3) are larger than those generated in homogeneous soil (Test1) at corresponding locations. Transducers P5 and P7 did not work properly during test1. Therefore a direct comparison between medium dense uniform soil in test 1 and dense soil in tests 2 and 3 at the same elevations in the free field can not be presented here. However, from similar comparison below structure (P3) shown in 
a)

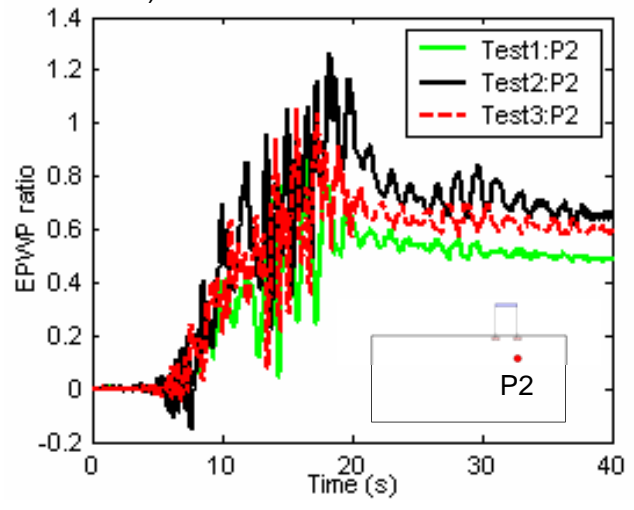

b)

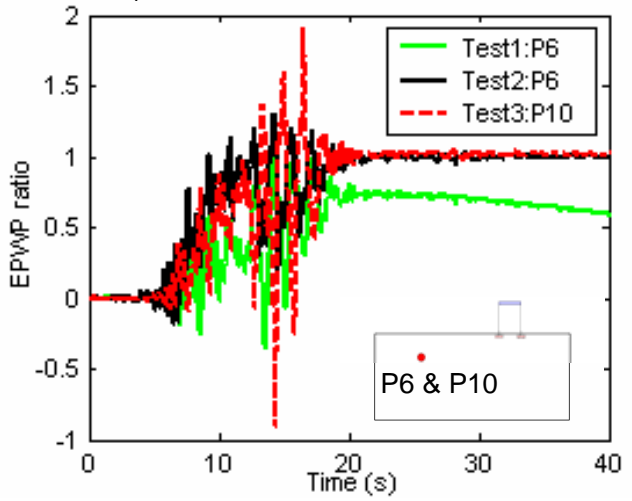

Figure 4. EPWP ratio time histories a) Below structure b) Free field

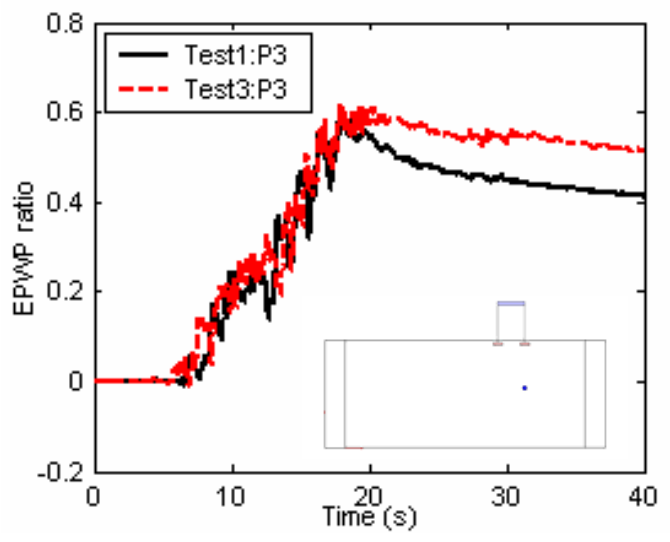

Figure 5. Comparison of EPWP ratio time histories between medium dense homogeneous soil (test 1 ) and dense soil (test 3) below structure

Figure 5 it is evident that EPWP ratio in dense sand in heterogeneous soil is larger than that in medium dense sand in uniform soil. The comparison of recorded EPWP ratio between medium dense uniform and dense sand at lower elevations in variable soil in the free field is shown in Figure 6. It has been observed that EPWP ratio near the ground surface (P6/P10 and higher) in heterogeneous soil has residual values of about one, indicating full liquefaction of the soil in these areas (both loose soil - e.g. P10 and dense soil - e.g. P5). However, the homogeneous soil did not liquefy.

Figure 7 shows the comparison of EPWP ratio between homogeneous and heterogeneous soil at the end of shaking ( $\mathrm{t}=20 \mathrm{~s})$. This result also indicates larger EPWP build-up in heterogeneous than in homogeneous soil. Although the heterogeneous soil deposit was on average denser than the uniform soil, its liquefaction resistance was lower than that of the uniform soil. Similar conclusions resulted from earlier numerical simulations (e.g. Popescu and Chakrabortty, 2006) and centrifuge tests (e.g. Ghosh and Madabhushi, 2003). From the results it is evident that soil heterogeneity is adversely affecting the liquefaction resistance. 
a)

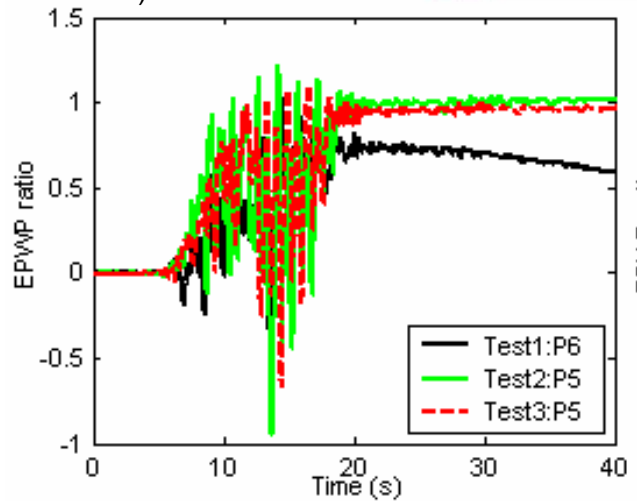

b)

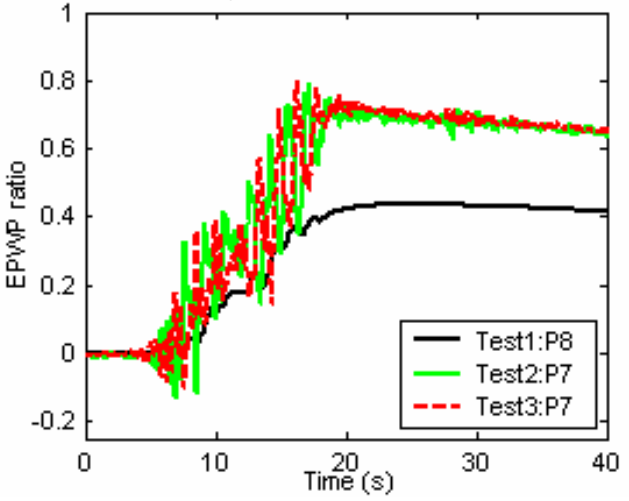

Figure 6. Comparison of excess pore water pressure between homogeneous and heterogeneous soil (dense zone) (a) P6 vs. P5 (b) P8 vs. P7

The results of the centrifuge tests also show amplification of the earthquake energy when seismic waves travel through soil. Figure 8 shows the comparison of the Arias intensity (Arias, 1970) evolution with time between homogeneous (Test1) and heterogeneous soil (Test3) in the free field.
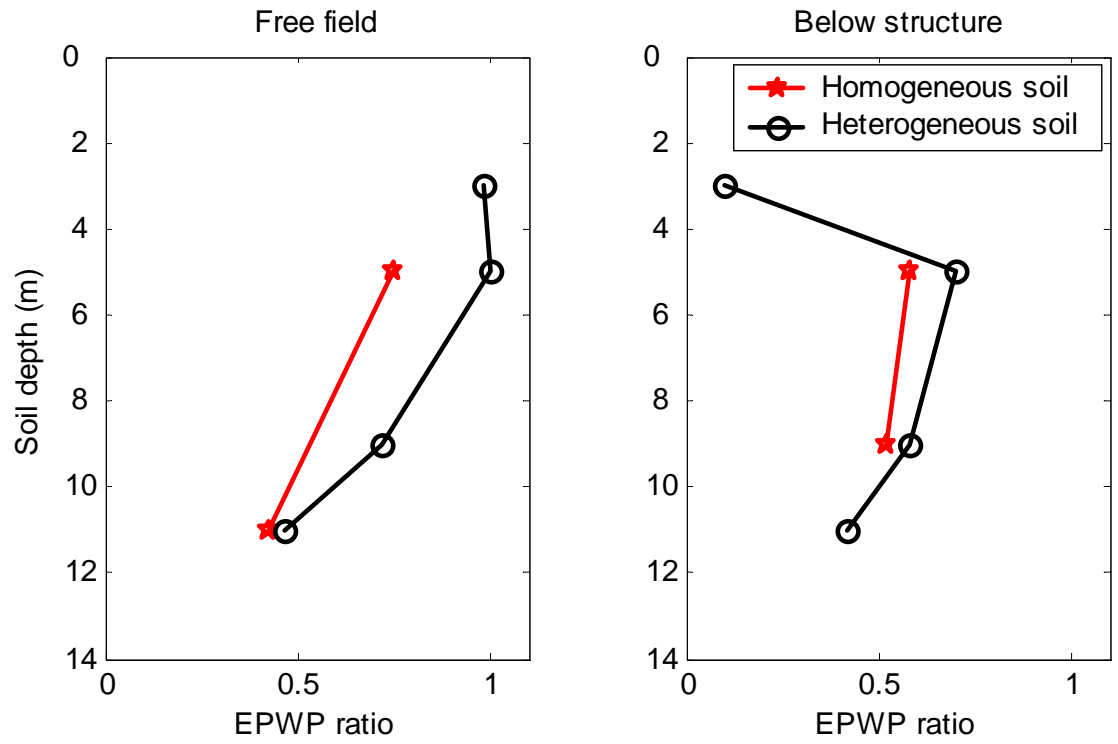

Figure 7. Comparison of excess EPWP ratio between homogeneous and heterogeneous soil at time $\mathrm{t}=20 \mathrm{~s}$ (in prototype scale) 


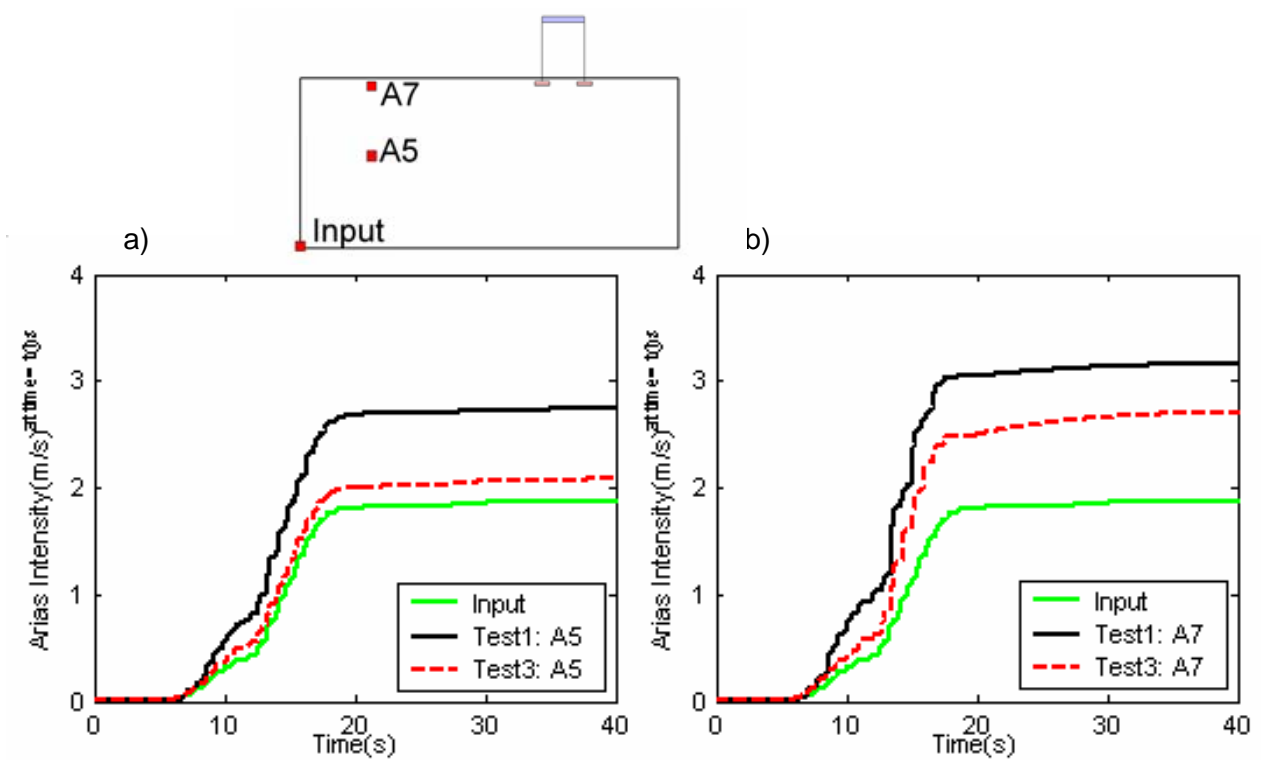

Figure 8. Comparison of Arias Intensity evolution with time in the free field between homogeneous and heterogeneous soil (a) Mid depth: A5 (b) Near surface A7

From the results shown in Figure $8 a$ (Input vs. A5) and 8b (input vs. A7) it is obvious that input motion is amplified more in homogeneous soil than in heterogeneous soil. Although the heterogeneous soil deposit was on average denser than the homogeneous soil, Arias intensity amplification was lower than that of the uniform soil due to higher EPWP build-up in the heterogeneous soil.

\section{Conclusions:}

A series of centrifuge tests have been conducted to investigate the seismic behaviour and liquefaction mechanism of heterogeneous soil. Experimental results such as accelerations, EPWP and settlements were monitored throughout the tests. From the study it was observed that although the heterogeneous soil deposit was on average denser than the uniform soil, its liquefaction resistance was lower than that of the uniform soil. Therefore, the experimental results support the findings of previous numerical research that more EPWP is generated in a heterogeneous soil deposit than in the corresponding homogeneous soil. From the study it is concluded that soil heterogeneity is adversely affecting the liquefaction resistance.

\section{Acknowledgements}

The financial support provided by NSERC under Research Grant No. RG203795-02 is gratefully acknowledged. The authors are also indebted to C-CORE Centrifuge Centre staff for their help during centrifuge tests.

\section{References}

Arias, A. 1970. A measure of earthquake intensity. Seismic design for nuclear power plants, Edited by R.J. Hansen. MIT Press. Cambridge, Mass., pp. 438-483.

Atigh, E. and Byrne, P.M. 2004. Liquefaction flow of submarine slopes under partially undrained condition: an effective stress approach. Canadian Geotechnical Journal, 41, pp. 154-165.

Budiman, J.S., Mohammadi, J. and Bandi, S. 1995. Effect of large inclusions on liquefaction of sand. In Proc. Conf. Geotechnical Engr. Div., Geotechnical Special Publication, 56, ASCE, pp. 48-63.

C-CORE. 2005. Earthquake induced damage mitigation from soil liquefaction- Data report: Centrifuge test CT8, March, CCORE report R-04-099-145, (http://www.civil.ubc.ca/liquefaction/availabledata.htm).

Chakrabortty, P., Jafari-Mehrabadi, A. and Popescu, R. 2004. Effects of low permeability soil layers on seismic stability of submarine slopes. Proc. $57^{\text {th }}$ Canadian Geotechnical Conf., Quebec City, PQ.

Ghosh, B. and Madabhushi, S.P.G. 2003. Effects of localized soil inhomogeneity in modifying seismic soil-structure interaction. Proc. $16^{\text {th }}$ ASCE Engineering Mechanics Conference, Seattle, WA, July.

Konrad, J-M. and Dubeau, S. 2002. Cyclic strength of stratified soil samples. In Proc. $55^{\text {th }}$ Canadian Geotechnical Conference: 
Ground and Water: Theory to Practice, Niagara Falls, ON, October, pp. 89-94

National Building Code of Canada (NBCC). 2005, Canadian commission on building and fire codes, National Research Council of Canada, Ottawa.

Popescu, R., Deodatis, G., and Nobahar, A. 2005. Effects of random heterogeneity of soil properties on bearing capacity, Probabilistic Engineering Mechanics, 20(4), October, pp-324-342.

Popescu, R., Prevost, J.H. and Deodatis, G. 1997. Effects of spatial variability on soil liquefaction: Some design recommendations, Geotechnique, 47(5):1019-36.

Popescu, R., Prevost, J.H., Deodatis, G. and Chakrabortty, P. 2006. Dynamics of nonlinear porous media with applications to soil liquefaction, Journal of Soil Dynamics and Earthquake Engineering, 26(6-7), June-July, pp. 648-665.

Popescu, R. and Chakrabortty, P. 2006. Liquefaction mechanism for heterogeneous soils, In proceedings Sea to sky geotechnique $-59^{\text {th }}$ Canadian geotechnical conference and $7^{\text {th }}$ joint CGS/IAH-CNC groundwater specialty conference, Vancouver, BC, Canada, October 1-4.

Prevost, J.H., 2002. Dynaflow - A nonlinear transient finite element analysis program, Version 02, Tech. Report, Dept. of Civil and Environmental Engineering, Princeton University, Princeton, NJ (http://www.princeton.edu/ dynaflow/).

Vaid, Y.P. and Eliadorani, A. 1998, Instability and liquefaction of granular soils under undrained and partially drained states, Canadian Geotechnical Journal, 35, pp. 1053-1062.

Vaid, Y.P. and Sivathayalan, S. 1996, Static and cyclic liquefaction potential of Fraser delta sand in simple shear and triaxial tests, Canadian Geotechnical journal, 33(2), April, pp. 281-289. 